\title{
WAP Domain
}

National Cancer Institute

\section{Source}

National Cancer Institute. WAP Domain. NCI Thesaurus. Code C13922.

The WAP (Whey Acidic Protein) Domain contains eight characteristically-spaced cysteine residues involved in disulphide bond formation and occurs in so-called 'four-disulphide core' proteins. The spatial pattern of these conserved domain cysteines suggests that the otherwise variable domain sequences may adopt a similar fold. The overall degree of domain sequence similarity is low; a few Pro and Gly residues are reasonably well conserved, as are polar/acidic residues between Cys3 and Cys4. WAP sequences are found in Whey Acidic Protein; Elafin (a human skin elastase-specific inhibitor); rat WDNM1 Protein (involved in metastatic potential); Kallmann Syndrome Protein; and guinea pig Caltrin-Like Protein II (inhibits calcium transport into spermatozoa). ( $\mathrm{NCl}$ ) 